khóa tại Bệnh viện đa khoa tỉnh Nam Định là một kết quả tốt, rất đáng khích lệ.

So sánh giữa các nhóm thây tỷ lệ tốt và rất tốt ở nhóm A1 đạt cao hơn cả (100\%), tiếp đến ở nhóm A2 (95.7\%) và nhóm A3 (66.7\%). Song vì số liệu từng nhóm ít nên khi so sánh thống kê X2 thì chưa có sự khác biệt có ý nghĩa giữa các nhóm ( $p>0,205)$.

Kết quả xa còn phụ thuộc vào các yếu tố như vận động sau mổ, sự hợp tác tuân thủ chế độ tập tại nhà cũng như điều kiện sức khỏe và độ tuổi của bệnh nhân có ảnh hưởng lớn đến kết quả điều trị.

\section{KẾT LUẬN}

Phương pháp kết hợp xương gãy liên mấu chuyển xương đùi bằng nẹp khóa là phương pháp kết xương vững chắc cho phép vận động và phục hồi chức năng sớm tránh được các biến chứng do bệnh nhân nằm lâu.

Đặc biệt đối với các bệnh nhân cao tuổi, có bệnh lý nội khoa kèm theo cân điều trị tích cực các bệnh nội khoa cũng như hướng dẫn bệnh nhân, người nhà tập phục hổi chức năng để đạt kết quả tốt.

\section{TÀI LIẸU THAM KHẢO}

1. Nguyễn Đắc Nghĩa (2006), Lưa chọn kỹ thuật điêu trị gãy đâu trên xương đùi ở người cao tuổi xem lại y văn, Tạp chí Y Dược học lâm sàng 108 , Số đăc biêt, 114-118.

2. Mai Châu Thu (2004), Đánh giá kết quả điều trị phẫu thuất gãy vùng mấu chuyển xương đùi ngườ lớn bằng nẹp gập góc liền khối tại bệnh viện Xanh pôn 2002-2004. Luận văn Bác sỹ் chuyên khoa II, Hoc viện Quân y.

3. Trần Quang Toản (2008), Đánh giá kết quả điều trị phẩu thuật gãy vùng mấu chuyển xương đùi người lớn bằng kết xương nẹp DHS tại bệnh viện Xanh pôn. Luận văn Thạc sỹ Y học, Học viện Quân y.

4. Lindskog D.M, Baumgaertner M.R (2004), Unstable Intertrochanteric hip Fractures in the Elderly, J. Am Acad Orthop Surg, 12, 179-190.

5. Nikunj Maru, Kishor Sayani (2013), Unstable Intertrochanteric Fractures In High Risk Elderly Patients Treated With Primary Bipolar Hemiarthroplasty: Retrospective Case Series, Gujarat Medical Journal, 68(2).

6. Erik N. Kubiak E. F., Eric S. and Kenneth A. (2006), The Evolution of Locked Plates, J. Bone Joint Surg, 88, 189-200.

\title{
ĐĂC ĐIỂM LÂM SÀNG VÀ CẬN LÂM SÀNG CỦA 612 BỆNH NHÂN XUẤT TINH MÁU TẠI BỆNH VIỆN ĐẠI HỌC Y HẦ NộI
}

\author{
Trần Phước Duy Bảo ${ }^{1}$, Lê Quốc Hưng ${ }^{2}$, Nguyễn Hoài Bắc ${ }^{2}$
}

\section{TÓM TẮT}

Để nhận biết các đặc điểm lâm sàng, cận lâm sàng của tình trạng xuất tinh máu ở nam giới, chúng tôi tiến hành nghiển cứu trên 612 bênh nhân nam bị xuất tinh máu. Kết quả cho thấy tuổi trung bình của các bệnh nhân trong nghiên cứu là 39,42 $\pm 11,67$ tuổi. Tỉ lệ bệnh nhân có tiên sử sử dụng rượu bia trong những lần xuất tinh có máu chiếm 22,45\%, tỉ lệ bệnh nhân ghi nhận có thói quen kìm hãm hay gián đoạn quan hệ khi xuất tinh chiếm 16,25\%. Tỉ lê bệnh nhân làm PCR lao dương tính chiếm $1,27 \%$. Tỉ lệ bệnh nhân có tPSA tăng chiếm $1,92 \%$. Tî lệ nuôi cấy dương tính chiếm $8,94 \%$. Nồng độ testosterone ở những bệnh nhân này khá thấp so với lứa tuổi, trong đó có $26,01 \%$ bệnh nhân có giá trị testosterone giảm ( $<12,1 \mathrm{nmol} / \mathrm{L}), 23,7 \%$ bệnh nhân có giá trị testosterone trong giới hạn thẩp $(12,1-15$

\footnotetext{
${ }^{1}$ Bệnh viện Đa khoa khu vực Thủ Đức

${ }^{2}$ Trường Đại học Y Hà Nội

Chịu trách nhiệm chính: Trân Phước Duy Bảo

Email: drduybao.dkkvthuduc@gmail.com

Ngày nhận bài: 17.3.2021

Ngày phản biên khoa học: 10.5.2021

Ngày duyệt bài: 19.5.2021
}

nmol/L). Tư khóa: Xuất tinh máu, yếu tố nguy cơ xuất tinh ra máu.

\section{SUMMARY}

\section{CLINICAL AND SUBCLINICAL CHARACTERISTICS OF 612 PATIENTS WITH HEMATOSPERMIA AT HANOI} MEDICAL UNIVERSITY HOSPITAL

To identify the clinical and subclinical features of hemospermia in men, we conducted a study on 612 male patients with hemospermia. The results showed that the average age of the patients in the study was $39.42 \pm 11.67$ years. Proportion of patients with a history of alcohol use in blood-occupied ejaculations $22.45 \%$, the proportion of patients reporting a habit of delaying or interrupting when ejaculation is occupied $16.25 \%$. The proportion of patients with positive PCR test for tuberculosis accounted for $1.27 \%$. The proportion of patients with tPSA increased by $1.92 \%$. The positive culture rate accounts for $8.94 \%$. The testosterone levels in these patients were quite low for age, of which $26.01 \%$ had decreased testosterone values $(<12.1 \mathrm{nmol} / \mathrm{L})$, and $23.7 \%$ had low testosterone values $12.1-15 \mathrm{nmol} / \mathrm{L})$. factors.

Keywords: Hematospermia, hematospermia risk 


\section{I. ĐẶT VẤN ĐỀ}

Xuất tinh máu là một tình trạng xuất hiện tế bào máu trong tinh dịch và có thể làm thay đổi màu sắc của tinh dịch khi xuất ra ngoài. Tình trạng này thường lặp đi lặp lại nhiều lần gây nên những ảnh hưởng không nhỏ lên sức khỏe tâm thần của bệnh nhân và bạn tình như: lo lắng, căng thẳng, hay thậm chí là trầm cảm.

Tỷ lệ xuất tinh máu trong cộng đồng hiện nay vẫn còn chưa được xác định chính xác. Theo Polito và các cộng sự, xuất tinh máu là một tình trạng ít gặp, chiếm khoảng $1 \%$ các bệnh nhân đển khám vì bệnh lý tiết niệu và nam khoa. Tình trang này thường xuất hiên ở nam giới trẻ dưới 40 tuổi và phần lớn là lành tính [1]. Trong một nghiên cứu ở Nhật Bản, có đến $88,9 \%$ các bệnh nhân bị xuất tinh máu (đã loại trừ các nguyên nhân u và viêm nhiễm) tự khỏi mà không cần điều trị với thời gian tự khỏi trung bình là 1,5 tháng kể từ khi xuất hiện triệu chứng [2]. Một nghiên cứu phân tích tổng quan gần đây cho thấy chỉ có 33 trường hợp có khối u $(25 \mathrm{ca} u$ tuyến tiền liệt) trong tổng số $931 \mathrm{ca}$ xuất tinh máu $(3,5 \%)$ [3]. Do đó, ta có thể thây đặc điểm các nguyên nhân dẫn đến tình trạng xuất tinh ra máu còn chưa được đánh giá đầy đủ.

Tại Việt Nam, vấn đề xuất tinh máu ít được quan tâm nên vấn chưa có nhiều nghiên cứu về vấn đề này. Ngoài ra, các ý kiến chuyên gia về vấn đề này lại chưa thống nhất.Trước đây người ta cho rằnghai nguyên nhân chính gây ra tình trang xuất tinh máu là ung thư tuyến tiền liệt và viêm túi tinh do lao. Hiên nay, viêm các cơ quan sinh dục được cho là nguyên nhân hàng đầu, trong đó tỷ lể lao của các cơ quan sinh dục là rất thấp. Điều này đã gây rất nhiêu khó khăn trong thực hành lâm sàng. Việc đánh giá chẩn đoán và điểu trị các trường hợp xuất tinh máu chủ yếu chỉ dựa theo kinh nghiệm cá nhân. Do đó, việc tìm hiểu các đặc điểm lẩm sàng và cận lâm sàng về tình trạng xuất tinh máu sẽ giúp các thầy thuốc lâm sàng đưa ra những đánh giá chẩn đoán và điều trị phù hợp, tránh được các đánh giá và can thiệp quá mức như sinh thiết tuyến tiền liệt và điêu trị lao đường sinh dục như hiện nay.

Xuất phát từ thực tế này, chúng tôi tiến hành nghiên cứu: "Đặc điểm lâm sàng và cân lâm sàng của 612 ca xuất tinh máu tại Bệnh viện Đại học Y Hà Nội"nhằm các mục tiêu sau:

1. Mô tả các đặc điểm lâm sàng và cận lâm sàng của những bệnh nhân xuất tinh máu khám tại Bệnh viên Đại học Y Hà Nội.

2. Tìm hiểu các yếu tố nguy cơ liên quan đến tình trạng xuất tinh máu dựa trên đặc điểm lâm sàng và cận lâm sàng của các bệnh nhân xuất tinh máu trong nhóm nghiên cứu.

\section{II. ĐỐI TƯƠNNG VÀ PHƯƠNG PHÁP NGHIÊN CỨU}

1. Đối tượng nghiên cứu. Tất cả các đối tượng bênh nhân bị xuất tinh ra máu hoăc phát hiện máu trong tinh dịch qua xét nghiệm tinh dịch đồ đến khám tại phòng khám Nam hoc Bệnh viện Đại học Y Hà Nội từ năm 2014 đến nắm 2020.

\section{Tiêu chuấn lứa chon:}

- Nam giới có độ tuối từ 16 đến 80 tuổi.

- Có triệu chứng xuất tinh ra máu, tiểu máu sau xuất tinh hoặc tình cờ phát hiện máu trong xét nghiệm tinh dịch đồ.

\section{Phương pháp nghiên cứu}

2.1. Thiết kế nghiên cứu: Mô tả cắt ngang.

2.2. Quy trinh nghiên cứu: Mỗi bệnh nhân được khai thác các thông tin bao gồm bênh sử, tình trang hôn nhân, tiền sử các bênh lý trước đó, đánh giá vị trí tinh hoàn và tuyến vú, lố tiểu thấp, các khối u tinh hoàn, giãn tĩnh mạch thừng tinh và các bất thường của ống dẫn tinh và mào tinh, thăm khám hậu môn trực tràng nhằm đánh giá đặc điểm tuyến tiền liệt. Các trường hợp có máu trong tinh dịch hay tiểu máu sau xuất tinh sẽ được hỏi cụ thể về hoàn cảnh xuất hiện triêu chứng, đặc điểm máu trong dịch xuất ra, đặc điểm nước tiểu sau xuất tinh, tiền sử can thiểp trên đường tiết niệu, tiền sử chấn thương tiết niệu - sinh duc.

Hoàn cảnh xuất tinh ra máu được hiểu trong 4 trường hợp:

- Thời gian chưa quan hê tình dục: khoảng thời gian tính từ lần quan hệ xuất tinh có máu đầu tiên đến lần quan hệ gần nhất trước đó.

- Quan hệ tình dục sau sử dụng rượu bia: là quan hệ tình dục ngay sau khi sử dụng rượu bia.

- Quan hê tình dục gián đoan - kìm hãm: là quan hê tình dục có sự chủ động kìm hãm xuất tinh để tiếp tục duy trì thời gian xuất tinh.

- Quan hệ tình dục mạnh: là quan hệ tình dục có cường độ mạnh, có cảm giác đau khi quan hệ.

Những bệnh nhân cũng được làm thêm các xét nghiệm xác định nguyên nhân và mức độ xuất tinh máu bao gồm tổng phân tích nước tiểu và nuôi cấy nước tiểu, PSA, dấu hiệu chỉ điểm của ung thư tinh hoàn (aFP và hCG), công thức máu, tinh dịch đồ, PCR lao. Một số trường hợp được chỉ định làm hình ảnh học (Siêu âm qua ngả trực tràng, MRI) nếu nghi ngờ có sự bất thường túi tinh, ống dẫn tinh, tuyến tiền liệt.

- Xử lý số liệu. Phần mềm R phiên bản 4.0.2 cho hệ điều hành Windows 10 được dùng để xử 
lý số liệu trong nghiên cứu này. Dữ liệu được trình bày dưới dạng trung bình, độ lệch chuẩn, trung vị, giá trị nhỏ nhất - lớn nhất.

\section{KẾT QUẢ NGHIÊN CứU}

1. Đặc điểm lâm sàng của nhóm nghiên cứu.

Bảng 1: Đăc điểm chung của nhóm nghiên cứu

\begin{tabular}{|c|c|c|c|c|c|}
\hline Đăc điếm & $\mathbf{N}$ & $\%$ & Trung bình \pm SD & Trung vị & GTNN-GTLN \\
\hline Tuối (năm) & 612 & & $39,42 \pm 11,67$ & 38 & $17-77$ \\
\hline$\leq 40$ & 365 & 59,64 & & & \\
\hline$>40$ & 247 & 40,36 & & & \\
\hline Chiều cao (cm) & 612 & & $166,94 \pm 5,37$ & 167 & $147-187$ \\
\hline Cân nặng (kg) & 612 & & $63,7 \pm 9,01$ & 63 & $41,8-106$ \\
\hline BMI (kg/m2) & 612 & & $22,8 \pm 2,8$ & 22.8 & $15,2-36,6$ \\
\hline$<18,5$ & 21 & 3,43 & & & \\
\hline $18,5-23$ & 362 & 59,16 & & & \\
\hline$>23$ & 229 & 37,41 & & & \\
\hline Tình trạng hôn nhân & 612 & & & & \\
\hline Có gia đình & 420 & 68,63 & & & \\
\hline Chưa có gia đình & 192 & 31,37 & & & \\
\hline Hút thuốc lá & 612 & & & & \\
\hline Có & 134 & 21,9 & & & \\
\hline Không & 478 & 78,1 & & & \\
\hline Tiên sử & 612 & & & & \\
\hline Khỏe mạn & 456 & 74,5 & & & \\
\hline Tăng huyết áp & 26 & 4,2 & & & \\
\hline Tiếu đường & 15 & 2,5 & & & \\
\hline Viêm tiết niệu - sinh dục & 22 & 3,6 & & & \\
\hline Sỏi tiết niệu & 11 & 1,8 & & & \\
\hline
\end{tabular}

Tỷ lệ nam giới bị xuất tinh máu dưới 40 tuối chiếm 59,64\%, trong đó độ tuối trung bình bị xuất tinh máu là 39,42 $\pm 11,67$. Đa số các bệnh nhân có tiên sử khỏe mạnh với tỷ lệ là 74,5\%.

Bảng 2: Đắc điểm hoàn cảnh xuất tinh ra máu

\begin{tabular}{|c|c|c|}
\hline Đặc điếm hoàn cảnh xuất tinh máu & $\mathbf{N}$ & $\%$ \\
\hline Thời gian chưa QHTD (tháng) & 597 & \\
\hline$\geq 1$ tháng & 20 & 3,35 \\
\hline$<1$ tháng & 577 & 96,65 \\
\hline QHTD sau sử dụng rượu bia & 597 & \\
\hline Có & 134 & 22,45 \\
\hline $\begin{array}{c}\text { Không } \\
\text { QHTD gián đoạn-kìm hãm }\end{array}$ & $\begin{array}{l}463 \\
597\end{array}$ & 77,55 \\
\hline Có & 97 & 16,25 \\
\hline $\begin{array}{c}\text { Không } \\
\text { QHTD mạnh }\end{array}$ & $\begin{array}{l}500 \\
597\end{array}$ & 83,75 \\
\hline
\end{tabular}

Trong số bệnh nhân đến khám vì xuất tinh máu, có 22,45\% bệnh nhân ghi nhận sử dụng rượu bia trước khi quan hệ tình dục có xuất tinh máu, có16,25\% trường hợp có quan hệ tình dục gián đoạn hay kìm hãm lúc quan hệ.

2. Đắc điểm cận lâm sàng của nhóm nghiên cứu

Bảng 3: Đăc đ̛̣iêm cận lâm sàng

Đăc điếm

\begin{tabular}{l|l|l} 
n & $\%$ & Trung bình \pm SD
\end{tabular} Tống phân tích tế bào máu ngoại vi

\begin{tabular}{|c|c|c|c|c|c|}
\hline Đặc điếm & n & $\%$ & Trung bình \pm SD & Trung vị & GTNN-GTLN \\
\hline \multicolumn{6}{|c|}{ Tống phân tích tế bào máu ngoại vi } \\
\hline $\begin{array}{c}\text { Hông câu } \\
<2.5 \mathrm{~T} / \mathrm{L}\end{array}$ & $\begin{array}{c}475 \\
1\end{array}$ & 0,21 & $5,3 \pm 0,63$ & 5,23 & $2,29-9,18$ \\
\hline$\geq 2.5 \mathrm{~T} / \mathrm{L}$ & 474 & 99,79 & & & \\
\hline Bạch câu & 475 & & $7,11 \pm 2,14$ & 6.79 & $3,19-19,1$ \\
\hline$\leq 10 \mathrm{G} / \mathrm{L}$ & 442 & 92,63 & & & \\
\hline
\end{tabular}

- Đạo đức nghiên cứu. Nghiên cứu được sự đông ý của Ban giám đốc bệnh viện Đại học Y gia nghiên cứu được đảm bảo bí mật. 
VIETNAM MEDICAL JOURNAL N ${ }^{0} 1$ - JUNE - 2021

\begin{tabular}{|c|c|c|c|c|c|}
\hline$>10 \mathrm{G} / \mathrm{L}$ & 35 & 7,37 & & & \\
\hline Tiếu câu & 475 & & $236,7 \pm 54,6$ & 235 & $79-528$ \\
\hline$<150 \mathrm{G} / \mathrm{L}$ & 14 & 2,94 & & & \\
\hline$\geq 150 \mathrm{G} / \mathrm{L}$ & 461 & 97,06 & & & \\
\hline$\frac{\mathrm{PSA}^{(\mathbf{n g} / \mathbf{m l})}}{\leq 4}$ & $\begin{array}{l}520 \\
510\end{array}$ & 98,08 & $1,09 \pm 0.98$ & 0.83 & $0.02-20.35$ \\
\hline $\begin{array}{c}4-10 \\
\text { AFP }(\mathrm{ng} / \mathrm{ml})\end{array}$ & 10 & 1,92 & & & \\
\hline $\begin{array}{c}\leq 10 \\
\leq 101\end{array}$ & 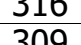 & 9778 & & & \\
\hline$>10$ & 7 & 2.22 & & & \\
\hline hCG (mIU/mL) & 312 & & & & \\
\hline$\leq 2$ & 284 & 91,03 & & & \\
\hline$>2$ & 28 & 8,97 & & & \\
\hline CRP-hs (mg/L) & 242 & & & & \\
\hline$\leq 5$ & 242 & 100 & & & \\
\hline $\begin{array}{c}>5 \\
\text { Tổng phân tích nước tiểu }\end{array}$ & $\begin{array}{c}0 \\
497\end{array}$ & 0 & & & \\
\hline Bình thường & 225 & 45,3 & & & \\
\hline Có hồng cầu & 242 & 48,7 & & & \\
\hline Có bạch cầu & 70 & 14,1 & & & \\
\hline Cấy nước tiếu & 179 & & & & \\
\hline Äm tính & 163 & 91,06 & & & \\
\hline $\begin{array}{l}\text { Dương tính } \\
\text { PCR lao }\end{array}$ & $\begin{array}{c}16 \\
158\end{array}$ & 8,94 & & & \\
\hline Am tính & 156 & 98,73 & & & \\
\hline Dương tính & 2 & 1,27 & & & \\
\hline Testosterone (nmol/L) & 519 & & $15,73 \pm 6.02$ & 15,07 & $2,9-70,49$ \\
\hline $\begin{array}{c}<12,1 \\
12,1-15\end{array}$ & $\begin{array}{l}135 \\
123\end{array}$ & $\begin{array}{c}26,01 \\
23,7\end{array}$ & & & \\
\hline$>15$ & 261 & 50,29 & & & \\
\hline \multicolumn{6}{|c|}{ Bất thường túi tinh trên Siêu âm/MRI } \\
\hline Bình thường & 208 & 53,47 & & & \\
\hline Viêm & 70 & 17,99 & & & \\
\hline Sỏi & 12 & 3,08 & & & \\
\hline Nang & 61 & 15,68 & & & \\
\hline Vôi hóa & 38 & 9,77 & & & \\
\hline
\end{tabular}

Tỉ lệ bênh nhân xuất tinh máu dương tính với trực khuẩn lao chỉ chiếm 1,27\%. Trong 179 trường hợp được cấy nước tiểu, có 16 trường hợp $(8,94 \%)$ dương tính, trong đó Enterococcus là tác nhân thường gặp nhất (4 trường hợp), tiếp đó là Staphylococcus aureus (2 trường hợp), Pseudomonas (2 trường hợp).

Các chỉ dấu ung thư phần lớn nằm trong giới hạn bình thường. PSA $\leq 4(\mathrm{ng} / \mathrm{ml})$ chiếm $98,08 \%$, aFP <10ng/ml chiếm $97,78 \%$, hCG $\leq 2$ $(\mathrm{mIU} / \mathrm{mL})$ chiếm $91,03 \%$. Trong số các trường hợp có bất thường aFP và hCG, không có trường hợp nào tăng đồng thời cả 2 chỉ dấu này. Có 10 bệnh nhân xuất tinh máu ghi nhận PSA nằm trong khoảng $4-10 \mathrm{ng} / \mathrm{ml}$, khi thăm khám hậu môn trực tràng không ghi nhận nhân cứng tuyến tiền liệt, đồng thời đánh giá tỉ lệ fPSA/tPSA >20\% ở cả 10 bệnh nhân.

Tỉ lệ bệnh nhân có nồng độ testosterone trong giới hạn thấp $(12,1-15)$ chiếm $23,7 \%$, hoặc giảm $(<12,1)$ chiếm 26,01\%.

\section{BÀN LUÂN}

Trong nghiên cứu của chúng tôi độ tuổi bệnh nhân gặp xuất tinh máu gặp từ 17 đến 77 tuổi (trung bình $39.42 \pm 11.67$ ). Kết quả này tương đồng với một báo cáo tại Trung Quốc của tác giả Li với khoảng độ tuổi bệnh nhân xuất tinh máu là 21 đến 77 tuổi (trung bình $39.8 \pm 10.60$ ) [5]. Điều này có thể được lý giải một phần do người Việt Nam và người Trung Quốc khá giống nhau về đặc điểm nhân chủng học và văn hóa Á Đông.

Theo nghiên cứu của chúng tôi, hoàn cảnh xuất tinh máu của 597 bệnh nhân, chúng tôi ghi nhận có 134 trường hợp (chiếm 22,45\%) có sử dụng rượu bia trong lần quan hệ có xuất tinh 
máu, 97 trường hợp (chiếm 16,25\%) có ghi nhận việc kìm hãm hay gián đoạn quan hệ khi xuất tinh. Kết quả này cho thây việc sử dụng rượu bia có thể gây giãn mạch và làm giảm sức bền thành mạch. Khi xuất tinh, sự co thắt mạnh và đột ngột của các cơ túi tinh, cơ thắt niệu đạo cũng như các cơ đáy chậu có thể gây tắng áp lực ở các tĩnh mạch dẫn đến xuất tinh ra máu. Một trong những giả thuyết tương tự cũng được đưa ra trước đây, đó là tình trạng xuất tinh máu có liên quan đển việc làm thay đổi áp lực trong lòng túi tinh khi rỗng đột ngột túi tinh đang căng phồng [6], cơ chế này còn giải thích cho việc kìm hãm hay gián đoạn quan hệ khi xuất tinh làm tăng nguy cơ xuất tinh máu.

Trong nghiên cứu của chúng tôi, có 158 bệnh nhân được làm PCR lao, chỉ có 2 trường hợp dương tính, chiếm tỉ lệ 1,27\%. Một nghiên cứu tại một trường đại học ở Iran cũng cho kết quả tương tự khi có 1 trường hợp dương tính với lao trong 157 trường hợp bệnh nhân bị xuất tinh máu [7]. Chúng tôi thực hiện xét nghiệm PSA cho 520 bệnh nhân xuất tinh máu, chỉ ghi nhận 10 trường hợp có giá trị tPSA $>4 \mathrm{ng} / \mathrm{ml}$ nhưng không có các dấu hiệu bát thường ở tuyến tiền liệt trên lâm sàng và tỉ lệ fPSA/tPSA > 20\%. Như vậy, quan điểm cho rằng ung thư tuyến tiền liệt và lao sinh dục là hai nguyên nhân chính của xuất tinh máu trong thực hành lâm sàng hiện nay chưa thật sự chính xác, điều này có thể liển quan đến sự tiến bộ trong công tác quản lý và điều trị bệnh Lao ở Việt Nam hiện nay so với trước đây.

Trong 179 trường hợp được chỉ định nuôi cây nước tiểu. Hầu hết trong số đó cho kết quả âm tính, chỉ có 16 trường hợp cấy dương tính. Trong đó có ba tác nhân chiếm tỉ lệ cao nhất là Enterococcus (4 trường hợp), Staphylococcus aureus (2 trường hợp), Pseudomonas (2 trường hợp). Tuy nhiên, đây đều là các vi khuẩn phổ biến trên da cũng như ở đường tiết niệu của người. Chính vì vậy, cách thức lấy mẫu có thể ảnh hưởng đến kết quả của xét nghiệm nuôi cấy vi khuẩn trong nước tiểu. Hơn nữa, có nhiều tác nhân gây bệnh lây truyền qua đường tình dục như Chlamydia, Mycoplasma và Ureaplasma là những vi khuẩn không thể nuôi cây trong các môi trường nuôi cấy phổ biến. Điều này dẫn đến kết quả nuôi cấy nước tiểu có thể chưa phản ánh chính xác đăcc điểm vi khuẩn học ở những bệnh nhân xuất tinh máu trong nhóm nghiên cứu. Do đó cần thêm các nghiên cứu khác với những xét nghiệm đặc hiệu hơn để đánh giá đầy đủ và chính xác đặc điểm vi khuẩn học ở bệnh nhân đến khám vì xuất tinh máu.

Khi đánh giá đường dẫn tinh bằng các phương tiện chẩn đoán hình ảnh, chúng tôi nhận thấy phần lớn các trường hợp xuất tinh ra máu không có sự bất thường cưa đường dẫn tinh. Trong những trường hợp bệnh lý, tình trạng viêm nhiễm của đường dần tinh chiếm tỷ lệ cao nhất (với 17,99\%). Kết quả này tương đồng với một nghiên cứu trước đó cho thấy tỳ lệ viêm nhiễm đường sinh dục cao ở những bệnh nhân xuất tinh ra máu [7]. Tương tự, các bất thường về đường phóng tinh như nang tuyến tiền liệt, nang ống Muller hay các nang ống phóng tinh cũng đã được phát hiện ở những bệnh nhân xuất tinh ra máu [8].

Trong nghiên cứu của chúng tôi, có đánh giá nồng độ nội tiết tố ở 519 bệnh nhân bị xuất tinh máu, kết quả nồng độ testosterone ở những bênh nhân này khá thấp so với lứa tuổi, trong đó có $26,01 \%$ bệnh nhân có nồng độ testosterone giảm dưới 12,1nmol/L, 23,7\% bệnh nhân có giá trị testosterone trong giới hạn thấp (12,1-15 nmol/L). Kết quả này gợi ý cho chúng tôi giả thuyết rằng nồng độ testosterone thấp là yếu tố nguy cơ của tình trạng xuất tinh máu. Tuy nhiên cần có thêm các nghiên cứu nhằm kiểm định giả thuyết này.

\section{KẾT LUẬN}

Kết quả nghiên cứu của chúng tôi cho thấy rằng phần lớn các bệnh nhân bị xuất tinh máu chưa rõ nguyên nhân. Những nguyên nhân được tìm thấy đa phần là lành tính. Những bệnh nhẩn bị xuất tinh máu do lao chiếm tỉ lệ thấp chỉ $1,27 \%$ trong số những nguyên nhân được tìm thấy.

Các yếu tố nguy cơ có thể liển quan đến tình trạng xuất tinh máu có thể kể đến là sử dụng rượu bia trước khi quan hệ tình dục, có sự kìm hãm hay gián đoạn trong khi quan hệ tình dục. Nồng độ testosterone giảm cũng có thể liên quan đển tình trạng xuất tinh máu, cần thêm nhiều nguyên cứu để kiểm chứng giả thuyết này.

\section{TÀI LIẸU THAM KHẢO}

1. Polito M., Giannubilo W., d'Anzeo G. và cộng sứ. (2006). Hematospermia: diagnosis and treatment. Arch Ital Urol Androl Organo Uff Soc Ital Ecogr Urol E Nefrol, 78(2), 82-85.

2. Furuya S., Masumori N., và Takayanagi $A$. (2016). Natural history of hematospermia in 189 Japanese men. Int J Urol, 23(11), 934-940.

3. Ahmad I. và Krishna N.S. (2007). Hemospermia. J Urol, 177(5), 1613-1618.

4. Li B.-J., Zhang C., Li K. và cộng sự. (2013). Clinical analysis of the characterization of magnetic resonance imaging in 102 cases of refractory 
haematospermia. Andrology, 1(6), 948-956.

5. Ganabathi, K., Chadwick, D., Feneley, R. C. L., \& Gingell, J. C. (1992). Haemospermia. British Journal of Urology, 69(3), 225-230.pdf.

6. Zargooshi J., Nourizad S., Vaziri S. và cộng sứ. (2014). Hemospermia: long-term outcome in 165 patients. Int J Impot Res, 26(3), 83-86.
7. Akhter W., Khan F., và Chinegwundoh F. (2013). Should every patient with hematospermia be investigated? A critical review. Cent Eur J Urol 66(1), 79-82.

8. Yagci C., Kupeli S., Tok C. và cộng sự. (2004). Efficacy of transrectal ultrasonography in the evaluation of hematospermia. Clin Imaging, 28(4), 286-290.

\section{NGHIÊN CỨU GÁNH NẶNG CHĂM SÓC BÊNNH NHÂN ALZHEIMER TẠI BÊ̂NH VIỆN LÃO KHOA TRUNG ƯO'NG NĂM 2020 - 2021}

\section{TÓM TẮT}

Mục tiêu: Mô tả gánh nặng chăm sóc bệnh nhân Alzheimer và một số yếu tố liên quan. Đối tượng và phương pháp: Nghiên cứu mô tả cắt ngang gánh nặng chăm sóc dựa trên thang điểm Zazit ở 52 người chăm sóc bệnh nhân Alzheimer tại Bệnh viện Lão Khoa Trung ương từ năm 2020 đến năm 2021. Kết quả: Gánh nặng chăm sóc trung bình của người chăm sóc theo thang điểm Zarit là 42,7 điểm. Trong đó, $57,7 \%$ trường hợp gánh nặng ở mức độ nghiêm trọng và rất nghiêm trọng. Gánh nặng chămm sóc có xu hướng tăng dần có ý nghĩa thống kê $(\mathrm{p}<0,05)$ theo thời gian chăm sóc bệnh nhân/ngày; thời gian mắc bệnh; giai đoạn sa sút trí tuệ; sự xuất hiện triệu chứng các triệu chứng giảm nhận biết, giảm sự chú ý, giảm tư duy, tính toán, giảm ngôn ngữ và hoạt động hàng ngày và các triệu chứng BPSD như hoang tưởng, kích động, mất ức chế, rối loạn vận động, rối loạn ăn uống và hành vi ban đêm. Kết luận: Gánh nặng chăm sóc bênh nhân Alzheimer của người chăm sóc là 42,7 điểm theo thang Zarit và có liên quan có ý nghĩa thống kê đến một số đặc điểm và mức độ nặng của triệu chứng bệnh.

Tư khóa: Alzheimer, gánh nặng chăm sóc, thang điểm Zarit.

\section{SUMMARY}

\section{THE CAREGIVER BURDEN OF PATIENTS WITH} ALZHEIMER'S DISEASE AT NATIONAL GERIATRIC HOSPITAL FROM 2020 TO 2021

Objective: Describe the burden of caring with Alzheimer's patients and related factors. Methods: A cross-sectional descriptive study about carving burden using ZBI on 52 caregivers of Alzheimer's patients at National Geriatric Hospital from 2020 to 2021. Results: The average caregiver burden on the ZBI is 42.7 points. In which, $57.7 \%$ of cases are severe and

\footnotetext{
${ }^{1}$ Bệnh viện Lão khoa Trung ương

2Trường Đai hoc Thăng Long

Chịu trách nhiệm chính: Nguyễn Ngọc Ánh

Email: ngocanh.nig@gmail.com

Ngày nhận bài: 19.3.2021

Ngày phản biên khoa hoc: 11.5.2021

Ngày duyệt bài: 21.5.2021
}

\section{Nguyễn Ngọc Ánh ${ }^{1}$, Đỗ Thị Khánh Hỳ 1,2}

very severe. The burden of care tends to increase with statistical significance $(p<0.05)$ according to the time of patient care/day; disease duration; stage of dementia; the occurrence of symptoms of reduced awareness, decreased attention, decreased thinking, reduced calculation, decreased language and daily functioning, and BPSD symptoms such as delusions, agitation, loss of inhibitions, dyskinesia, eating disorders and nocturnal behavior. Conclusions: Caregiver's burden of care with Alzheimer's is 42.7 ZBI and significantly associated with several characteristics and symptom severity.

Key words: Alzheimer, burden of caregiver, Zarit Burden Interview

\section{I. ĐĂT VẤN ĐỀ}

Ngày nay, sự già hóa dân số có xu hướng ngày càng tăng kéo theo sự gia tăng tỷ lệ mắc các bệnh thoát hóa, trong đó có sa sút trí tuệ. Theo tổ chức $Y$ tế thế giới WHO ước tính có 50 triệu người mắc sa sút trí tuệ năm 2018, khoảng 10 triệu trường hợp mới mẳc hàng năm và dự kiến lền đến 130 triệu người mắc vào năm 2050 [1]. Nguyên nhân sa sút trí tuệ thường gặp nhất là bệnh Alzheimer chiếm $50-70 \%$ [1]. Đa số bênh nhân Alzheimer sống tại nhà, cân có người chăm sóc và theo dõi, trở thành gánh nă̆ng chăm sóc cho gia đình và xã hội. Các ảnh hưởng về tình cảm và tâm lý của người chăm sóc chủ yếu được biểu hiện bằng gánh nặng khách quan và chủ quan. Gánh nặng khách quan là những ảnh hưởng do những công việc phục vụ bệnh nhân ví dụ như trợ giúp hoạt động hàng ngày (ăn uống, tắm rửa, đi vệ sinh, uống thuốc...) trong khi đó gánh nặng chủ quan là cảm nhận của người chăm sóc về gánh nặng [2]. Thang đánh giá gánh nặng Zarit (Zarit Burden Inventory - ZBI) được phát triển gồm 22 câu hỏi tự đánh giá, điểm càng cao tương ứng với gánh nặng càng lớn. ZBI đã được Việt hóa và sử dụng với độ tin cậy cao [3]. Bệnh viện Lão khoa Trung ương có chương trình quản lý chăm sóc và theo 